\title{
Pancreatic stents: Why? When?
}

STUART SHERman, MD, GLEN A LeHMAN, MD

S SHERmAN, GA LehMAN. Pancreatic stents: Why? When? Can J Gastroenterol 1993;7(6):485-492. Placement of endoprosthesis in the biliary tree is a well-established therapeutic modality. Application of similar techniques to the pancreas are emerging. Pancreatic duct stents have been placed to seal duct disruptions, bridge dominant strictures, drain pseudocysts, treat symptomatic minor and/or major sphincter stenosis, bypass obstructing pancreatic duct stones, prevent procedure-induced pancreatitis and serve as a guide for sphincterotomy. In this review, the authors will analyze the current indications and complications associated with pancreatic duct stent therapy. Selection of appropriate candidates appears important for optimal results of therapy. However, definite recommendations are difficult to make because there are few controlled studies, follow-up in most series is brief and there are no comparison studies of endoscopic versus surgical therapy. At present, conservatism is the appropriate general rule in these therapeutic endeavours.

Key Words: Chronic pancreatitis, Pancreas divisum, Pancreatic pseudocysts, Pancreatic strictures, Stents

\section{Endoprothèse pancréatique: Pourquoi? Comment?}

RÉSUMÉ: La pose d'une endoprothèse dans l'arbre biliaire est une modalité thérapeutique reconnue. L'application de techniques similaires au niveau du pancréas se répand. Des endoprothèses au niveau du canal pancréatique ont été installées pour colmater des brèches, pour établir des ponts entre des rétrécissements majeurs, drainer des pseudokystes, traiter des sténoses symptomatiques mineures et/ou majeures, contourner des calculs obstruant le canal pancréatique, prévenir la pancréatite pouvant résulter d'une intervention et servir de guide pour la sphinctérotomie. Dans ce bilan, les auteurs analyseront les indications actuelles et les complications associées au traitement par endoprothèse au niveau du pancréas. La sélection des candidats semble importante pour l'obtention de résultats optimum. Il est cependant difficile de formuler des recommandations précises, puisque les études contrôlées sont peu nombreuses, dans la plupart des séries, le suivi est bref et aucune étude comparative n'a encore porté sur le traitement endoscopique versus chirurgical. À l'heure actuelle, la règle générale favorise un certain conservatisme en matière d'approches thérapeutiques.

Division of Gastroenterology/Hepatology, Indiana University Medical Center, Indianapolis, Indiana, USA

Correspondence: Dr Glen A Lehman, Division of Gastroenterology/Hepatology, Indiana University Medical Center, 550 North University Boulevard, Room 2300, Indianapolis, IN 46202-5250 USA. Telephone (317) 274-4821, Fax (317) 274-0975
E NDOSCOPIC PLACEMENT OF POLY. ethylene stents is a well-established therapy for treating various benign and malignant biliary tract diseases. Although still in infancy, application of similar techniques in the pancreas are emerging. Pancreatic duct stents have been placed to seal duct disruptions, bridge dominant strictures, drain pseudocysts, treat symptomatic minor (ie, pancreas divisum) and/or major (ie, sphincter of Oddi dysfunction) sphincter stenosis, bypass obstructing stones, prevent procedure-induced pancreatitis and to serve as a guide for sphincterotomy (1) (Table 1$)$. In this review, we analyze the current indications and complications associated with pancreatic duct stent therapy. Data in this area are often difficult to interpret because of the heterogenous populations with one or more pathological processes being treated (eg, pancreatic duct stones, strictures, pseudocysts) and because of the multiple therapies being performed in a given patient (eg, stricture dilation, stone extraction, bile duct and/or pancreatic duct sphincterotomy). Currently, conservatism is the appropriate general rule in these therapeutic endeavours. As with many newly evolving developments in medicine, controlled trials and firm data are limited.

\section{BRIDGE DOMINANT STRICTURES}

Benign strictures of the main pancreatic duct may be a complication of previously embedded stones or a conse- 


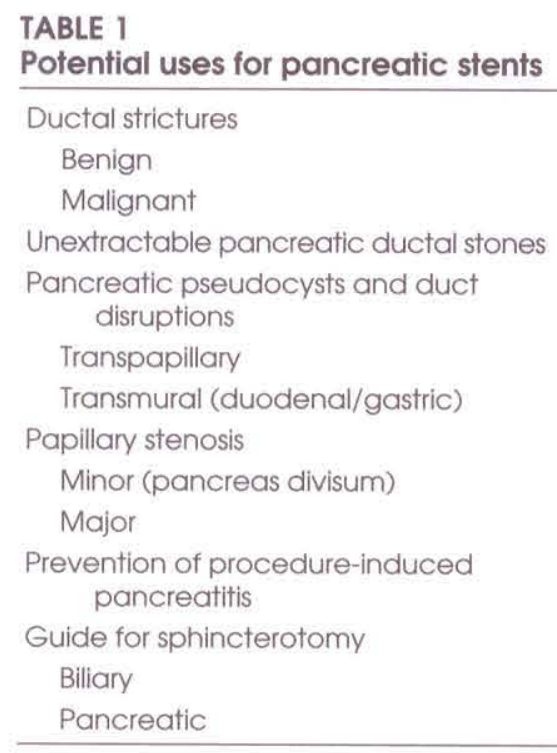

quence of acute inflammatory changes around the main pancreatic duct (2). In Cremer's large referral population, only $10 \%$ of the patients presented with a stricture without associated calcified pancreatic stones (2). Pancreatic duct strictures can be treated by stent therapy. Endoscopic therapy (and surgical therapy) aims to alleviate the obstruction to exocrine juice outflow. If stents larger than 7 French are to be used, patients often require both pancreatic and bile duct sphincterotomies followed by stricture dilation. Pancreatic duct stones should be removed, if possible. Probably the best candidates for stenting are those patients with a distal stricture (in the pancreatic head) and upstream dilation (type IV pancreatitis).

Results of pancreatic duct stent placement (usually with ancillary procedures) are shown in Table $2(2-6)$. Successful stent placement was achieved in 73 to $100 \%$ of patients. Fifty-four per cent of patients reported benefit from therapy with eight- to 37 month follow-up. Methods used to quantitate the degree of improvement are often poorly defined. Partial symptom improvement after stenting indicates that intraductal hypertension was an etiological factor. Continued symptom relief after stent removal indicates adequate dilation of the narrowing. Differentiation of these two types of improvement is, unfortunately, not clarified in some reports.
In the largest reported series (2), 75 (of 76 attempted) patients with severe chronic pancreatitis (primarily alcohol-related), distal pancreatic duct stricture and upstream dilation underwent stenting of the main pancreatic duct through the major papilla $(n=54)$ or minor papilla $(n=21)$ (to dilate the narrowing and to decompress the upstream duct) using a 10 French stent. All patients had undergone a biliary and pancreatic sphincterotomy, stricture dilation and extracorporeal shockwave lithotripsy (ESWL) (most patients) to fragment pancreatic duct stones. Stent placement was achieved in $98.7 \%$. Stents were clinically thought to remain patent for a mean of 12 months (range two to 38 ), ie, patients developed recurrent pain at that time. A dramatic decrease or complete relief of pain was initially observed in $94 \%$ of the patients and was associated with a decrease in the main pancreatic duct diameter. Disappearance of the stricture was observed in only seven of 64 nonoperated patients after 13 months (range two to 30 ) of stent therapy. Eleven patients underwent pancreaticojejunostomy after confirmation of pain reduction with main pancreatic duct decompression. The remainder required (long term) repeated stent changes. Early complications were related to the pancreatic and/or biliary sphincterotomy. 'Pancreatic juice infection', due to stent clogging, developed in eight patients, and three had their stent migrate inwardly. Fifty-five per cent of nonoperated patients remained symptom-free at a mean followup of three years $(2,7)$. Stent therapy was believed by the authors to be an acceptable medium term treatment of pain associated with a main pancreatic duct stricture. Unfortunately, because the stricture persisted in the majority, compliance with long term use of such stents, ie, multiple stent changes being required, would be difficult. As a result, the expandable stents (18 French diameter, $23 \mathrm{~mm}$ long) have been tried in 29 patients (7). Early follow-up to six months was encouraging and stent clogging was not seen.

There is limited information regarding therapy of malignant pancreatic duct strictures for pain control (8). As with stent therapy of benign strictures, bypassing the malignant obstruction may reduce the intraductal pressure and result in pain relief. However, because the pancreatic duct is usually disrupted in pancreatic cancer patients, it is often difficult to pass a guidewire through the stricture for purposes of stent placement.

\section{PANCREATIC DUCTAL STONES}

There is debate as to whether pancreatic calculi aggravate the clinical course of chronic pancreatitis (manifested as increased abdominal pain and/or recurrent attacks of acute pancreatitis) or are just the inevitable sequelae of ongoing gland destruction. It has been postulated that increased intraductal pressure proximal (upstream) to an obstructed focus within the pancreatic duct is one of the potential mechanisms responsible for attacks of acute pancreatitis or exacerbations of chronic abdominal pain in patients with chronic pancreatitis with or without stones $(6,9)$. Reports indicating that endoscopic (with or without ESWL) or surgical removal of pancreatic calculi results in improvement in symptoms support this notion $(5,10-16)$.

No study reported to date specifically addresses the use of pancreatic stents to bypass obstructing stones. However, in several series, stents were used for this indication with associated pain improvement $(5,16)$. We attempted to identify those patients with predominantly main pancreatic duct stones most amenable to endoscopic removal and to determine the effects on the patient's clinical course with such removal (16). Thirty-two patients with ductographic evidence of chronic pancreatitis and pancreatic duct stones underwent attempted endoscopic removal using various techniques, including bile duct and/or pancreatic duct sphincterotomy, stricture dilation, pancreatic duct stenting, stone basketing, balloon extraction and/or flushing. Of these patients, $71.9 \%$ had complete or partial stone removal and $67.7 \%$ improved after endoscopic therapy. Symptomatic improvement was most evident in the group of patients with 
TABLE 2

Results of pancreatic duct stenting for dominant strictures

\begin{tabular}{lcccccc}
\hline Author, year & $\begin{array}{c}\text { Number of patients } \\
\text { attempted }\end{array}$ & $\begin{array}{c}\text { Technical } \\
\text { success }\end{array}$ & $\begin{array}{c}\text { Mean F/U } \\
\text { (months) }\end{array}$ & $\begin{array}{c}\text { Number of } \\
\text { patients improved }\end{array}$ & Major complication & Death \\
\hline Huibregtse, 1988 & 11 & $8(73 \%)$ & 20 & 7 & 2 (unknown) & 0 \\
McCarthy, 1988 & 5 & $5(100 \%)$ & 14 & 4 & 2 (unknown) & 0 \\
Kozarek, 1989 & NA & $3(100 \%)$ & 8 & 3 & 0 & 0 \\
Grimm, 1989 & 63 & $55(87 \%)$ & 19 & $31^{*}$ & 20 (unknown) & 1 \\
Cremer, 1991 & 76 & $75(99 \%)$ & 37 & $41^{\dagger}$ & 12 & 1 \\
Total & 155 & $143(92.3 \%)$ & - & $86(53.5 \%)^{\dagger}$ & $36(23.2 \%) \dagger$ & $1 \%$ \\
\hline
\end{tabular}

F/U Follow-up: NA Not available; "Estimate; ${ }^{\dagger}$ Includes beneficial effects of stone extraction with or without lithotripsy in 68 patients

chronic relapsing pancreatitis (versus those presenting with chronic continuous pain alone, $83.3 \%$ versus $46.2 \%$ ). Factors favouring stone removal included: three or less stones; stones confined to the head and the body of the pancreas; absence of a downstream stricture; stone diameter $10 \mathrm{~mm}$ or less; and absence of impacted stones. The only complication from therapy was mild pancreatitis in $8.2 \%$. These data suggest that removal of pancreatic duct stones may result in symptomatic improvement.

One would anticipate that bypassing pancreatic duct stones with a pancreatic stent would also result in similar clinical benefit. However, because multiple stent changes are required, this is not a long term solution for the management of pancreatic duct stones. Certainly, short term stenting to bypass obstructing stones may be useful, as the stent may serve to crush the stone mechanically, facilitating extraction on a subsequent endoscopic procedure. Overall, the endoscopist is encouraged to remove pancreatic stones in symptomatic patients when they are located in the main pancreatic duct and are thus readily accessible. ESWL can be used to facilitate fragmentation and stone removal when endoscopic therapy alone fails. In the short term, pancreatic duct stenting can be used to bypass obstructing stones, either as a diagnostic trial for pain improvement or to facilitate stone crushing and subsequent removal.

\section{PANCREATIC PSEUDOCYST AND FISTULA}

Pancreatic pseudocysts are defined as encapsulated collections (without an epithelial lining) of pancreatic juice,

\section{TABLE 3}

\section{Endoscopic treatment of pancreatic pseudocysts"}

\begin{tabular}{|c|c|c|c|c|c|c|}
\hline Author, year & $\mathrm{n}$ & $\begin{array}{l}\text { Trans- } \\
\text { papillary }\end{array}$ & ECG & ECD & Morbidity & Mortality \\
\hline Kozarek, 1985 & 4 & - & 3 of 3 & 1 of 1 & 2 & 1 \\
\hline Huibregtse, 1988 & 7 & 5 of 6 & - & 1 of 1 & 1 & 0 \\
\hline Grimm, 1989 & 16 & 5 of 7 & 1 of 1 & 8 of 8 & 5 & 1 \\
\hline Cremer, 1989 & 33 & - & 11 of 11 & 21 of 22 & 3 & 0 \\
\hline Sahel, 1991 & 37 & - & 1 of 3 & 31 of 34 & 5 & 1 \\
\hline Kozarek, 1991 & 18 & 12 of 14 & - & - & 5 & 0 \\
\hline Total & 115 & 22 of $27(81 \%)$ & 16 of $18(89 \%)$ & 62 of $66(94 \%)$ & $19 \%$ & $2.7 \%$ \\
\hline
\end{tabular}

"Numbers refer to the frequency of technical success (number successful of number attempted): ECD Endoscopic cystoduodenostomy; ECG Endoscopic cystogastrostomy

either pure and/or containing necrotic debris and/or blood, which are situated either outside or within the limits of the pancreas from which they arise (17). Conventional therapy for symptomatic pancreatic pseudocysts has been primarily surgical. More recently, percutaneous and endoscopic techniques have been employed.

Two endoscopic approaches can be applied, depending on whether the cyst communicates with the pancreatic duct $(5,6,17-20)$ (Table 3). Cysts communicating with the ductal system and located in the head and/or body of the pancreas can be drained by a transpapillary approach $(6,20)$. The proximal tip of the endoprosthesis has generally been placed into the cystic cavity (17). A pancreatic duct sphincterotomy may be required. As with all indications for pancreatic stenting, the size, length and shape of the endoprosthesis should be adapted to the anatomy and diameter of the duct. Kozarek and colleagues (20) employed transpapillary pancreatic duct drains or stents in 18 patients with pancreatic duct disruption which were associated with peripancreatic fluid collections in 14. Eight nasopancreatic drains and 19 pancreatic duct stents were placed. The drains were placed into large fluid collections for a mean of five days and were often exchanged for stents. Pancreatic duct stents were used for smaller fluid collections, usually to bridge the ductal disruption (median time: six weeks, range: one to 18 months). Sixteen of 18 patients had resolution of the disrupted pancreatic duct. The peripancreatic fluid collection resolved in 12 of 14 . Complications were limited to mild exacerbations of pancreatitis in four (two associated with stent occlusion) and recurrent duct disruption and pseudocyst formation in one. Stent-induced ductal changes developed in nine patients. At a median follow-up of 16 months, seven patients (39\%) required elective surgery for ongoing pain $(n=4)$ or residual/recurrent fluid collections $(n=3)$.

Noncommunicating pseudocysts can be treated by direct cystoenterostomy via the stomach (endoscopic cystogastrostomy [ECG]) or duodenum (endoscopic cystoduodenostomy [ECD]). The aim of therapy is to create a communication between the cystic cavity and the gastric or duodenal lumen. Two prerequisites should be ful- 
filled before attempting this treatment: bulging due to the cyst should be obvious during upper endoscopy; and the distance between the cyst and the lumen should not exceed $1 \mathrm{~cm}$ (17). This distance can usually be assessed by computed tomography, ultrasound or endosonography; however, when the compression is visible, the cyst-to-lumen distance is usually less than $1 \mathrm{~cm}$. The cyst wall should be mature and unilocular. A needle knife is used to bore a hole into the cyst cavity. Because cyst fluid can rapidly escape and obscure the view, access should be quickly restored. A cystoenterotome which allows the endoscopist to maintain access to the cyst cavity after cutting is now commercially available (21). Puncture should be performed perpendicular to the cyst; thus a duodenoscope is usually used. One or more stents or nasocystic tubes are then left in place for a few weeks until the cyst cavity has disappeared.

In a series of 33 chronic pancreatitis patients with symptomatic pseudocysts, ECD was performed in 22 with periduodenal cysts and ECG in 11 with retrogastric cysts (19). ECD was successfully performed in 21 (95.4\%). On immediate follow-up, no residual cyst was evident. Pain disappeared in $95.2 \%$ and relief of cholestasis and duodenal stenosis was observed in 10 of 10 . No significant complications occurred after successful ECD. Peritonitis developed in one patient after a failed procedure. At a mean follow-up of 31 months (range three to 84 ), recurrent pseudocysts developed in $9 \%$. ECD was a definitive treatment in $86.4 \%$ (19 of 22). ECG was successfully performed with associated pain relief in all 11 patients. Two complications occurred: hemorrhage and pseudocyst infection. One patient had incomplete regression of the pseudocyst and required percutaneous drainage. Two patients had recurrent pseudocysts at a mean time of 18.4 months (range three to 39 ). Thus, ECG was a definitive treatment in eight of 11 patients. Sahel and colleagues (17) performed cystoenterostomy (primarily ECD) in 37 patients. Nearly all cysts were successfully drained. Major complications consisted of retroperitoneal perforation $(n=3)$ and hemorrhage $(n=2)$, one of which resulted in death when surgery was refused. Late follow-up (mean 37.2 months) in 22 patients revealed excellent results in 19 (no cyst recurrence and disappearance of pain).

These excellent results certainly support the use of cystoenterostomy in appropriate candidates. When compared with other endoscopic techniques, however, this procedure has a relatively high bleeding and perforation rate. Nevertheless, the overall complication rate probably compares favourably with surgical series. Coordination with a surgeon is necessary when performing this procedure.

\section{PANCREAS DIVISUM}

Pancreas divisum, the most common congenital variant of pancreatic ductal anatomy, occurs when the ductal systems of the dorsal and ventral pancreatic ducts fail to fuse during the second month of gestation. With nonunion of the ducts, the major portion of the pancreatic exocrine juice drains into the duodenum via the dorsal duct and the minor papilla. It has been proposed that a relative obstruction to pancreatic exocrine juice flow through the minor papilla could result in pancreatic pain and/or acute pancreatitis in a subpopulation of patients with pancreas divisum $(22,23)$. Although several epidemiological studies dispute the relation of pancreas divisum and pancreatitis, two lines of evidence favour this association. First, histological studies and pancreatograms have demonstrated signs of chronic pancreatitis isolated to the dorsal pancreas. Second, several reports have indicated that symptoms may be relieved by facilitating dorsal duct decompression endoscopically or surgically.

Endoscopic attempts to decompress the dorsal duct in patients with symptomatic pancreas divisum have been performed primarily by dilation, stent insertion and/or minor papilla sphincterotomy. McCarthy (4) placed 5 or 7 French dorsal duct stents in 19 pancreas divisum patients presenting with recurrent pancreatitis or abdominal pain. Seventeen were improved at fol- low-up (six months to three years). Stent therapy was complicated by pancreatitis $(10 \%)$, stent occlusion ( $21 \%)$, stent migration out $(8 \%)$ or into (4\%) the pancreatic duct and dorsal duct changes of chronic pancreatitis (11\%). Satterfield and associates (24) reported improvement in acute recurrent pancreatitis patients treated by dorsal duct dilation \pm pancreatic stenting. No patient with chronic pancreatitis benefitted from this therapy. Lans and colleagues (25) recently reported their results of a randomized controlled trial of long term (12 months) stenting of the minor papilla in patients with recurrent pancreatitis $(n=19)$. Follow-up continued for at least 12 months after stent removal. Stented patients had fewer hospitalizations and episodes of pancreatitis $(\mathrm{P}<0.05)$ and were more frequently judged to be improved $(90 \%$ versus $11 \%$ for controls, $\mathrm{P}<0.05)$. Although symptomatic improvement following this therapy has been encouraging, multiple stent changes are generally required. Interestingly, these authors reported no stent-induced pancreatic ductal changes (see below) and postulated that their alteration of the stent length with stent changes prevented this complication.

A 'more permanent' enlargement of the minor papilla orifice is possible from sphincterotomy. Preliminary studies using minor papilla sphincterotomy for pancreas divisum patients presenting with acute pancreatitis suggested that the majority improved $(26,27)$. We attempted to evaluate the efficacy of minor papilla endoscopic sphincterotomy for pancreas divisum patients $(n=52)$ presenting with disabling pancreatic type pain $(n=24)$, idiopathic acute recurrent pancreatitis $(n=17)$ or chronic pancreatitis $(n=11)$ (28). Our technique is to place a short, 5 to 7 French dorsal duct stent in the minor papilla and then perform a 3 to $5 \mathrm{~mm}$ sphincterotomy over the stent using the stent as a guide for cutting and a bridge to prevent edema-induced closure of the cut. The stent is then removed in approximately two weeks. Although $76.5 \%$ of the acute recurrent pancreatitis group improved following therapy, only $26.1 \%$ of the chronic 
pain group $(\mathrm{P}=0.002)$ and $27.3 \%$ of the chronic pancreatitis group $(\mathrm{P}=0.01)$ benefitted. These discordant results in responsiveness to therapy for the acute recurrent pancreatitis group versus the chronic pancreatitis and chronic pain group were noted in several surgical series evaluating dorsal duct decompression $(29,30)$. Pancreatitis complicating therapy occurred in $13.3 \%$, but generally was mild and managed conservatively. Stent-induced dorsal duct changes occurred in $50 \%$. One elderly patient died from complications of a pancreatic abscess that developed after a failed attempt at minor papilla cannulation (and intent to place a stent).

Results of the above series indicate that progress is being made in the management of this difficult patient population. Selection of pancreas divisum patients for therapy remains a problem. Results of these studies suggest that patients with acute recurrent pancreatitis are good candidates, whereas patients with chronic pancreatitis and/or chronic pain alone do not do as well. Further trials comparing medical, surgi$\mathrm{cal}$ and endoscopic therapy are awaited. Moreover, the best endoscopic approach to these patients (ie, minor papilla sphincterotomy versus long term stenting versus dilation) needs further evaluation.

\section{SPHINCTER OF ODDI DYSFUNCTION}

Endoscopic retrograde cholangiopancreatography (ERCP) with sphincter of Oddi manometry (SOM) may be helpful in defining the etiology of unexplained pancreatitis. SOM may reveal an elevated basal sphincter pressure in 15 to $57 \%$ of such patients $(31,32)$. Although an abnormal basal sphincter pressure may be confined to the pancreatic duct segment (particularly in patients with idiopathic pancreatitis), relief of symptoms may follow standard endoscopic sphincterotomy in 55 to $90 \%$ of patients (standard endoscopic sphincterotomy usually completely severs the common channel sphincter and part of the sphincter choledochus, but leaves the pancreatic duct sphincter untouched) (33).

Residual pancreatic duct sphincter hypertension may account for the lack of improvement following endoscopic sphincterotomy in some patients. Limited data are available evaluating various endoscopic therapies for these patients. Pancreatic duct stenting has been shown to be effective in only $47 \%$ of patients with short term follow-up $(3,4)$. Such stenting is not a long term solution, but may identify candidates for pancreatic duct sphincter ablation. Unfortunately, the outcome from short term stenting may be difficult to interpret because stenting can produce some pain or pancreatitis. Moreover, small diameter ( 5 to 7 French) stents often occlude after just two to four weeks (34). Guelrud (35) evaluated the efficacy of hydrostatic balloon dilation (6 $\mathrm{mm}$ diameter) in 17 idiopathic pancreatitis patients who had pancreatic duct sphincter hypertension following standard endoscopic sphincterotomies. Sixty-nine per cent benefitted from this treatment at a mean follow-up of one year. A larger study with control patients and a longer term follow-up are necessary before balloon dilation can be advocated. Moreover, the complication rate of balloon dilation appears unacceptably high. A limited number of pancreatic duct endoscopic sphincterotomies have been performed, but follow-up is too short for assessment of outcome (36). Currently, it appears that the best approach to a severely disabled patient with residual pancreatic duct sphincter hypertension is to perform a pancreatic duct septoplasty.

\section{PREVENTION OF POST- PROCEDURE PANCREATITIS}

Postprocedure pancreatitis may occur in as many as $10 \%$ of patients after difficult, traumatic or repeated cannulations or after multiple pancreatic duct injections (37). In part, this pancreatitis may be due to edema and sphincter of Oddi spasm with restriction of pancreatic juice flow. Thus, in theory, pancreatic stenting may alleviate the obstruction and reduce the risk of postprocedure pancreatitis. In a randomized, controlled study, 37 patients who were at high risk for development of post-ERCP pancreatitis were treated either with placement of a nasopancreatic catheter or with conventional therapy (38). There was a trend towards less frequent $(55 \%$ for control subjects versus $37 \%$ for stented patients) and less severe postprocedure pancreatitis in the stented group.

Endoscopic sphincterotomy for sphincter of Oddi dysfunction (SOD) is associated with an overall complication rate of $10.8 \%$; pancreatitis occurs in $7.8 \%(39)$. The risk is considerable in the setting of small diameter common bile ducts. It has been postulated that the hypertrophic or fibrotic sphincter in patients with SOD increases the risk of pancreatitis because extended periods of high intensity current may be required to sever the sphincter. The effect of prophylactic main pancreatic duct stenting on the incidence of endoscopic sphincterotomy-induced pancreatitis in $98 \mathrm{pa}$ tients with SOD and/or a small diameter common bile duct (less than $6 \mathrm{~mm}$ ) was recently completed (40). Short $(2$ to $2.5 \mathrm{~cm}) 5$ to 7 French pancreatic duct stents were placed at endoscopic sphincterotomy and left in place for 10 to 14 days in 43 patients. The remaining 50 patients were treated conventionally. Stent placement failed in five patients. Postprocedure pancreatitis occurred in $14 \%$ of the stented patients and in $18 \%$ treated without stents. The frequency of postsphincterotomy pancreatitis was greatest in patients with a small diameter common bile duct and/or pancreatic duct (in the head of the pancreas), but was unaltered by stenting. The results of these two trials suggest that prophylactic main pancreatic duct stenting does not reduce the incidence of post-procedure pancreatitis in high risk patients.

\section{GUIDE FOR SPHINCTEROTOMY}

Deep cannulation is required for standard endoscopic sphincterotomy. When this cannot be achieved, precutting may be required (41). In many of these patients, the pancreatic duct can be easily cannulated, allowing for passage of a guidewire and placement of a short, 2 to $3 \mathrm{~cm}$ pancreatic stent. Needle knife sphincterotomy can then be 
performed using the stent as a guide. The general direction of cutting is oriented towards the $11: 00$ to $12: 00$ position. The pancreatic stent serves as a guide to identify the pancreatic duct orifice and aids in directing the cut. Once the bile duct is entered, the sphincterotomy can be completed in standard fashion. It remains uncertain whether leaving the stent in the pancreatic duct for a week or two is necessary.

Pancreatic sphincterotomy can be performed in a fashion similar to precut biliary sphincterotomy. This technique may be considered in patients who have had a prior biliary sphincterotomy for SOD dysfunction, but have residual pancreatic sphincter hypertension documented by SOM. The best method to ablate the pancreatic sphincter, however, remains controversial. Traditionally, surgical sphincteroplasty has been used in this setting. Alternatively, placement of a pancreatic stent and needle knife septotomy can be done. The cut is usually made in the $12: 00$ position for approximately $5 \mathrm{~mm}$. However, the most appropriate length and depth of the cut is unknown. The use of pancreatic stents in these settings should be considered experimental and not recommended for general use.

\section{PANCREATIC STENT \\ PLACEMENT TECHNIQUE}

The technique for placing a stent in the pancreatic duct is similar to the techniques used for inserting a biliary stent. A guidewire must be maneuvred upstream to the narrowing. Hydrophilic, flexible tipped wires are especially helpful for bypassing strictures. Torqueable wires are occasionally necessary. The stent is then advanced over the guidewire using a pusher tube.

Most pancreatic stents are just standard biliary stents with extra side holes at approximately $1 \mathrm{~cm}$ intervals to (hopefully) permit better side branch juice flow. Modifications of the standard double flanged polyethylene stents have been developed. Removal of the internal flange(s) may reduce the frequency of intraductal stent migration (42).

In general, the size of the stent should not exceed the size of the normal downstream duct. Therefore, 5 to 7 French stents are commonly used in small ducts, whereas 10 to 11.5 French stents can be used in patients with advanced chronic pancreatitis and grossly dilated ducts. Most diagnostic trial or short term therapy stents are left in place for two to four weeks. In contrast, long term therapy stents have been left in place for three to 38 months. The need for stent exchange or removal depends on whether the disease being treated has resolved.

\section{COMPLICATIONS ASSOCIATED WITH PANCREATIC STENTS}

True complication rates are difficult to decipher due to the heterogenous populations treated and the lack of a uniform definition of a complication and grading system of their severity (43). Complications related directly to stent therapy include stent occlusion, stent migration and stent-induced ductal changes. The rate of pancreatic stent occlusion appears to be similar to that for biliary stents (34). We found that $80 \%$ of pancreatic stents (primarily 5 to 7 French) were occluded within eight weeks of placement when carefully evaluated by water flow methods. More than $80 \%$ of these early occlusions were totally silent, ie, not associated with increased pain or clinical pancreatitis. In such circumstances, the stent is, perhaps, serving as a dilator or a wick.

Stent migration may be upstream or downstream. Migration in either direction may be heralded by return of pain or pancreatitis. Johanson and colleagues (44) reported inward migration in $5.2 \%$ of patients and duodenal migration in $7.5 \%$. Although proximal stent migration into the duct is relatively uncommon, surgery may be required to retrieve the stent.

A worrisome side effect of polyethylene pancreatic duct stents are morphological changes in the pancreatic duct, which occur in the majority of patients $(45,46)$. Kozarek $(45)$ recently reported the anatomical alterations of the pancreatic duct induced by such stents. Thirty-four patients had 38 pancreatic ductal stents ( 5 to 7 French with additional side holes) placed for disrupted pancreatic duct with pseudocyst $(\mathrm{n}=11)$, hypertensive pancreatic duct sphincter after biliary sphincter ablation $(n=11)$, pancreatic duct stricture $(n=7)$ or recurrent pancreatitis in the setting of pancreas divisum $(n=5)$. The stents were removed or exchanged at a mean time of four months (range two weeks to 24 months). Nine patients had occluded stents, six of whom had new ductal changes - diffuse duct dilation $(n=4)$, new pseudocyst $(n=1)$, enlargement and infection of an existing pseudocyst $(n=1)$. With stent change or removal, five of the six ductal changes resolved, whereas one duct remained moderately dilated (at six months after stent removal).

Changes characteristic of chronic pancreatitis developed in three patients at anatomical sites contiguous with the stent. At follow-up (after stent removal), the pancreatic duct normalized in one patient (at three months), improved in another (residual stricture and side branch ectasia at six months) and was mildly dilated in the third (at three months). Overall, $36 \%$ of all patients (including $72 \%$ of patients who had normal initial pancreatograms) had subsequent ductal changes.

A preliminary report confirms these stent-induced changes in previously normal pancreatic ducts (46). In that series, 36 patients were treated with 5 to 7 French stents, 3 to $12 \mathrm{~mm}$ long, for four to 22 months (exchanges at one- to nine-month intervals). Mild to marked pancreatic ductal changes were noted in 30 patients $(83 \%)$ at stent removal. Of the 14 patients who underwent follow-up ERCP (six to 12 months after stent removal), 12 ( $86 \%$ ) had normalization of their pancreatogram. Similar pancreatic stent-induced changes have been reported by others $(4,47)$.

Although therapeutic benefit has been reported for pancreatic stenting, these studies reveal that morphological changes of the pancreatic duct directly related to this therapy occur in the majority of patients. Limited observations to date indicate a tendency of these ductal changes to improve with time following stent change and/or removal 
$(45,46)$. In a recently abstracted, randomized study (48), the frequency of pancreatic ductal changes induced by stenting ( 5 to 7 French stents placed for one year with stent changes every three to six months) and catheter dilation (every six months for one year) were compared in patients with acute recurrent pancreatitis, and normal SOM and pancreatograms. Ductal changes developed in $61 \%$ of the stented group $(n=26)$ and $11 \%$ of the dilated group $(n=28)$. One year after completion of therapy, $23 \%$ of the stented group had persistent ductal changes compared with $18 \%$ in the dilation group.

It remains uncertain what the long term consequences of these stent-induced changes are. Moreover, histological data in humans have been limited to a few pancreatic head resections where advanced fibrosis has been seen in previously stented areas (49). In patients with advanced chronic pancreatitis, further stent-induced scar may be inconsequential. In contrast,

\section{REFERENCES}

1. Geenen JE, Rolny P. Endoscopic therapy of acute and chronic pancreatitis. Gastrointest Endosc 1991;37:377-82.

2. Cremer M, Deviere J, Delhaye M, et al. Stenting in severe chronic pancreatitis: Results of medium-term follow-up in 76 patients. Endoscopy 1991;23:171-6.

3. Kozarek RA, Patterson DJ, Ball TJ, et al. Endoscopic placement of pancreatic stents and drains in the management of pancreatitis. Ann Surg 1989;209:261-6.

4. McCarthy J, Geenen JE, Hogan WJ. Preliminary experience with stent placement in benign pancreatic diseases. Gastrointest Endosc 1988;34:16-8.

5. Huibregtse K, Schneider B, Vrij AA, et al. Endoscopic pancreatic drainage in chronic pancreatitis. Gastrointest Endosc 1988;34:9-15.

6. Grimm H, Meyer WH, Nam VC, et al. New modalities for treating chronic pancreatitis. Endoscopy 1989;21:70-4.

7. Cremer M, Deviere J, Delhaye M, et al. Non-surgical management of severe chronic pancreatitis. Scand J Gastroenterol 1990;25(Suppl 175):77-84.

8. Harrison MA, Hamilton JW. Palliation of pancreatic cancer pain by endoscopic stent placement.

Gastrointest Endosc 1989;35:443-5. stent-induced damage in a normal pancreas may have more significant long term consequences.

We recently completed a pilot study evaluating the frequency, severity and reversibility of stent-induced pancreatic ductal changes in the normal dog pancreas (50). Six animals were stented for two to four months. Radiographic, gross and histological abnormalities developed in each dog. The radiographic findings (stenosis in the stented region with upstream dilation) were associated with gross evidence of fibrosis which increased proportionately with the length of the stenting. Histological changes of obstructive pancreatitis were present in most experimental dogs. Although the results of this study may not be directly applied to humans, they strongly suggest that caution is warranted, particularly when placing pancreatic stents into patients with normal pancreatic parenchyma, ie, no chronic pancreatitis. Further studies addressing the issues of stent diameter,

9. Schneider MU, Lux G. Floating pancreatic duct concrements in chronic pancreatitis. Endoscopy 1987;17:8-10.

10. Ponsky JL, Duppler DW. Endoscopic sphincterotomy and removal of pancreatic duct stones. Am J Surg 1987;53:613-6.

11. Fuji T, Amano H, Harima K, et al. Pancreatic sphincterotomy and pancreatic endoprosthesis. Endoscopy 1985; 17:69-72.

12. Sauerbruch T, Holl T, Sackman M, Paumgartner G. Extracorporeal lithotripsy of pancreatic stones in patients with chronic pancreatitis and pain: A prospective follow-up study. Gut 1992;33:969-72.

13. Delhaye $M$, Vandermeeren A, Baize M, Cremer M. Extracorporeal shock-wave lithotripsy of pancreatic calculi. Gastroenterology 1992;102:610-20.

14. Hansell DT, Gillespie G, Imrie CW. Operative transampullary extraction of pancreatic calculi. Surg Gyn Obstet 1986;163:17-20.

15. Kozarek RA, Ball TJ, Patterson DJ. Endoscopic approach to pancreatic duct calculi and obstructive pancreatitis. Am J Gastroenterol 1992;87:600-3.

16. Sherman S, Lehman GA, Hawes RH, et al. Pancreatic ductal stones: Frequency of successful endoscopic removal and improvement in composition and duration of therapy as they relate to efficacy and safety are needed. Evaluation of expandable (both coated and uncoated) stents is just beginning. Until such data are available, widespread use of the currently available pancreatic stents is not recommended.

\section{CONCLUSIONS}

Endoscopic placement of pancreatic stents is an exciting new area for the endoscopist. Selection of appropriate candidates appears important for optimal results of therapy. Unfortunately, at present, definitive recommendations are hard to make because there are few controlled studies, follow-up in most series is brief and there are no comparison studies of endoscopic versus surgical therapy. Endoscopists are reminded to exercise caution when placing pancreatic stents as serious, long term complications may occur. Further prospective, randomized controlled studies are encouraged.

symptoms. Gastrointest Endosc 1991;37:511-7.

17. Sahel J. Endoscopic drainage of pancreatic cysts. Endoscopy 1991;23:181-4.

18. Kozarek RA, Brayko CM, Harlan R, et al. Endoscopic drainage of pancreatic pseudocysts. Gastrointest Endosc 1985;31:322-7.

19. Cremer M, Deviere J, Engelholm L. Endoscopic management of cysts and pseudocysts in chronic pancreatitis: Long-term follow-up after 7 years of experience. Gastrointest Endosc 1989;35:1-9.

20. Kozarek RA, Ball TJ, Patterson DJ, et al. Endoscopic transpapillary therapy for disrupted pancreatic duct and peripancreatic fluid collections. Gastroenterology 1991;100:1362-70.

21. Cremer M, Devier ], Baize M, et al. New device for endoscopic cystoenterostomy. Endoscopy 1990;22:76-7.

22. Cotton PB, Kizu M. Malfusion of dorsal and ventral pancreas; a cause of pancreatitis. Gut 1977;18:A400.

23. Gregg JA. Pancreas divisum: Its association with pancreatitis. Am J Surg 1977;134:539-43.

24. Satterfield ST, McCarthy JH, Geenen JE, et al. Clinical experience in 82 patients with pancreas divisum: Preliminary results of manometry and endoscopic therapy. Pancreas $1988 ; 3: 248-53$ 
25. Lans JI, Geenen JE, Johanson JF, Hogan WJ. Endoscopic therapy in patients with pancreas divisum and acute pancreatitis: A prospective, randomized, controlled trial. Gastrointest Endosc 1992;38:430-4.

26. Sohendra N, Kempeneers I, Nam VC, et al. Endoscopic dilation and papillotomy of the accessory papilla and internal drainage in pancreas divisum. Endoscopy 1986;18:129-32.

27. Liguory C, Lefebvre JF, Canard JM, Bonnel D, Fritsch L, Etienne JP. Le pancreas divisum: Etude clinique et therapeutique chez l'homme. A propos de 87 cas. Gastroenterol Clin Biol 1986;10:820-5.

28. Lehman GA, Sherman S, Nisi R, Hawes RH. Pancreatic divisum: Results of minor papilla sphincterotomy. Gastrointest Endosc 1993;39:1-8.

29. Keith RG, Shapero TF, Saibil FG, Moore TL. Dorsal duct sphincterotomy is effective long-term treatment of acute pancreatitis associated with pancreas divisum. Surgery 1989;106:660-7.

30. Warshaw AL, Simeone JF, Schapiro $\mathrm{RH}$, et al. Evaluation and treatment of the dominant dorsal duct syndrome. Am J Surg 1990;159:59-66.

31. Toouli J, Roberts-Thompson IC, Dent J, et al. Sphincter of Oddi motility disorders in patients with idiopathic recurrent pancreatitis. $\mathrm{Br} \mathrm{J}$ Surg 1985;72:859-63.

32. Venu RP, Geenen JE, Hogan W, et al. Idiopathic pancreatitis: An approach to diagnosis and treatment. Dig Dis Sci $1989 ; 34: 54-60$.
33. Lans JL, Parikh NP, Geenen JE. Applications of sphincter of Oddi manometry in routine clinical investigations. Endoscopy 1991;23:139-43.

34. Ikenberry SO, Silverman WB, Ruffolo TA, et al. Pancreatic stent occlusion rate. Gastrointest Endosc 1991;37:266A.

35. Guelrud M. Papillary stenosis. Endoscopy 1988;20(Suppl):193-202.

36. Watanapa P, Williamson RCN. Pancreatic sphincterotomy and sphincteroplasty. Gut 1992;33:865-7.

37. Sherman S, Lehman GA. ERCP-and endoscopic sphincterotomy-induced pancreatitis. Pancreas 1991;6:350-67.

38. Shakoor T, Hogan WJ, Geenen JE. Efficacy of nasopancreatic catheter in the prevention of post-ERCP pancreatitis: A prospective randomized controlled trial. Gastrointest Endosc 1992;38:251A.

39. Sherman S, Ruffolo TA, Hawes RH, Lehman GA. Complications of endoscopic sphincterotomy: A prospective series with emphasis on the increased risk associated with sphincter of Oddi dysfunction and nondilated bile ducts. Gastroenterology 1991;101:1068-75.

40. Smithline A, Silverman WB, Ruffolo TA, et al. Effect of prophylactic main pancreatic duct stenting on the incidence of biliary endoscopic sphincterotomy induced pancreatitis in high risk patients. Gastrointest Endosc 1992;38:262A.

41. Shakoor T, Geenen JE. Precut papillotomy. Gastrointest Endosc 1992;38:623-7.

42. Johanson JF, Schmalz MJ, Geenen JE.
Migration of pancreatic duct stents prevented by a simple modification. Gastrointest Endosc 1991;37:272A.

43. Cotton PB, Lehman G, Vennes J, et al. Endoscopic sphincterotomy complications and their management: An attempt at consensus. Gastrointest Endosc 1991;37:383-93.

44. Johanson JF, Schmalz MJ, Geenen JE. Incidence and risk factors for biliary and pancreatic stent migration. Gastrointest Endosc 1992;38:341-6.

45. Kozarek RA. Pancreatic stents can induce ductal changes consistent with chronic pancreatitis. Gastrointest Endosc 1990;36:93-5.

46. Derfus GA, Geenen JE, Hogan WJ. Effect of endoscopic pancreatic duct stent placement on pancreatic ductal morphology. Gastrointest Endosc 1990;36:206A.

47. Rossos PG, Kortan P, Haber GB. Complications associated with pancreatic duct stenting. Gastrointest Endosc 1992;38:252A.

48. Burdick JS, Geenen JE, Venu RP, et al. Ductal morphological changes due to pancreatic stent therapy - a randomized controlled study. Am J Gastroenterology 1992;87:155A

49. Siegel JH. Decompression techniques. In: Siegel JH, ed. Endoscopic Retrograde Cholangiopancreatography: Technique, Diagnosis, and Therapy. New York: Raven Press, 1992:272-363.

50. Sherman S, Alvarez C, Robert M, Ashley S, Reber H, Lehman G. Polyethylene pancreatic duct stent-induced changes in the normal dog pancreas, Gastrointest Endosc. (In press) 


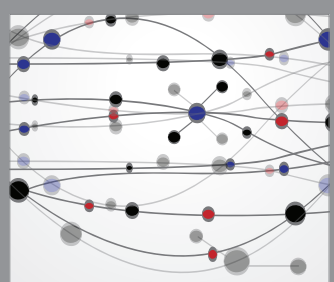

The Scientific World Journal
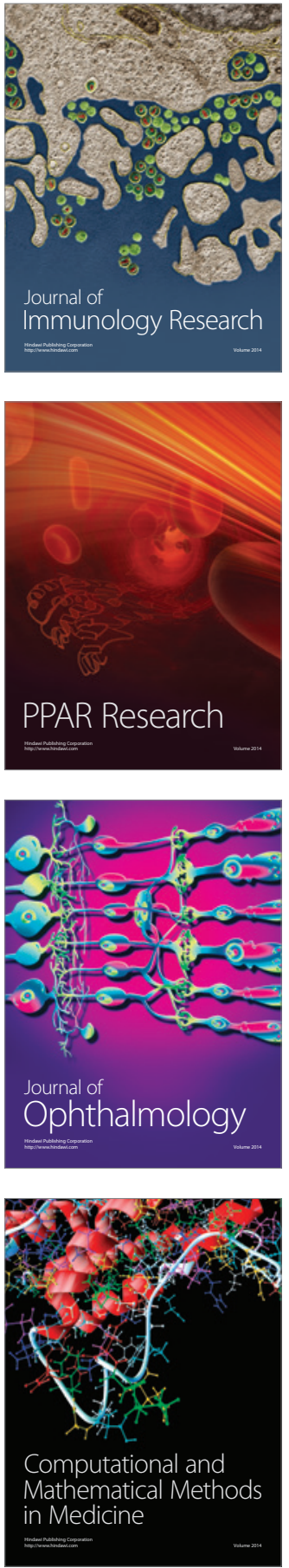

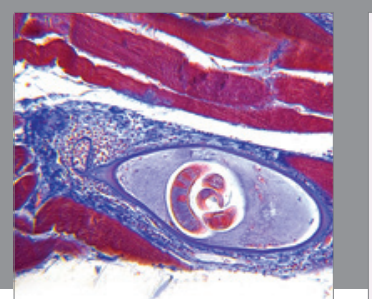

Gastroenterology Research and Practice

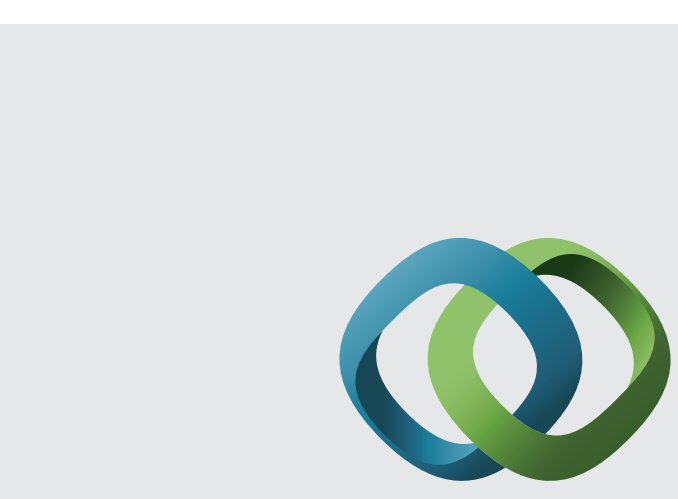

\section{Hindawi}

Submit your manuscripts at

http://www.hindawi.com
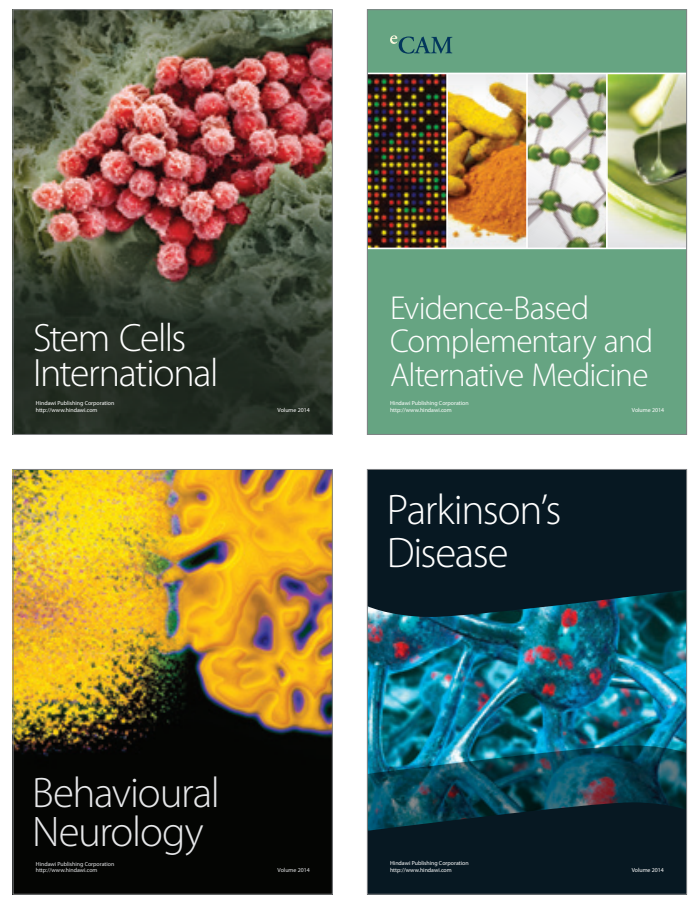
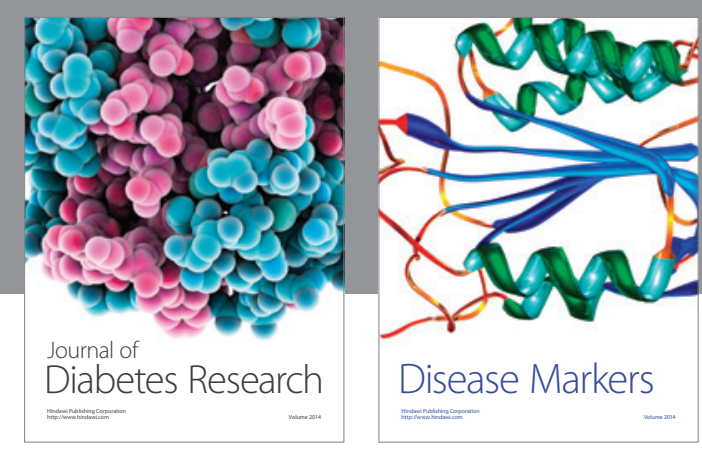

Disease Markers
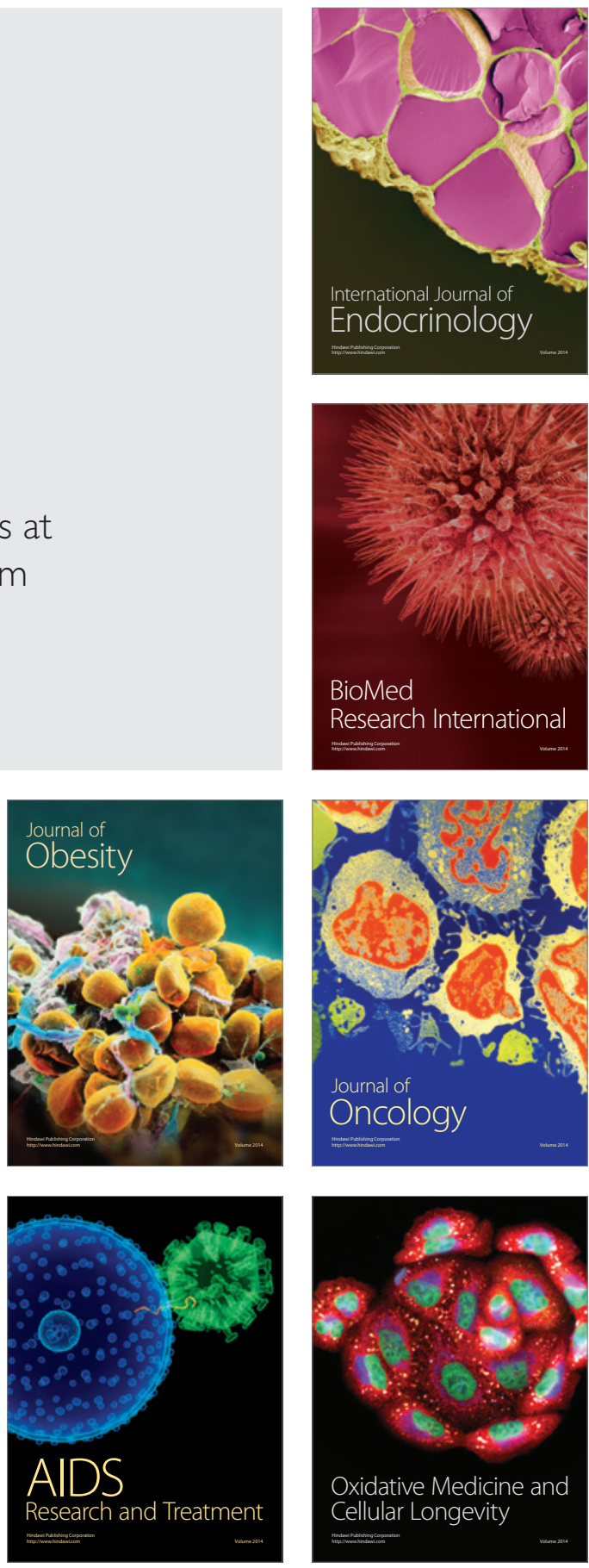